\title{
De Dynamische Patiënt Simulator als toetsvorm
}

P.M. Bloemendaal, J.M. van Baalen, S. Eggermont

\section{Samenvatting}

Medisch studenten moeten aan het einde van hun opleiding in staat zijn zelfstandig besluiten te nemen. Om studenten in staat te stellen deze besluitvaardigheid te trainen heeft de Afdeling Heelkunde van het Leids Universitair Medisch Centrum (LUMC) de Dynamische Patiënt Simulator (DPS) ontwikkeld. Centraal in dit computerprogramma staat de toestand van de patiënt, die tijdens het verloop van het programma verandert. Studenten moeten zelfstandig een keuze maken uit de diagnostische en therapeutische mogelijkheden die de simulatie toelaat. De DPS registreert naast de handelingen van de student ook de volgorde en het tijdstip hiervan. Vanuit deze registratie wordt een cijfer berekend. Dit cijfer wordt samen met de feedback op het handelen van de student aan het einde van de casus gepresenteerd. Omdat de studenten hun kennis in een klinische situatie moeten toepassen, kan de DPS als een praktijkgerichte toets ingezet worden.

\section{Inleiding}

In de opleiding leert de student zelfstandig te handelen in verschillende vakgebieden van de geneeskunde. ${ }^{1} \mathrm{Om}$ dit doel te bereiken is het noodzakelijk dat studenten kennis en kunde verwerven op diverse vlakken van de geneeskunde en daarnaast leren om zelfstandig problemen aan te pakken en af te handelen. Hierbij zal van de studenten een steeds grotere besluitvaardigheid gevraagd moeten worden naarmate zij verder komen in de opleiding. Het begrip besluitvaardigheid kan als volgt geoperationaliseerd worden:

- inschatten van de ernst van de situatie;

- nemen van de medisch correcte besluiten;

- op het juiste tijdstip nemen van besluiten;

- in de goede volgorde nemen van besluiten;

- satisfactie van de beslisser over de genomen besluiten.

Om studenten tijdens hun opleiding in staat te stellen om te oefenen met het nemen van beslissingen, heeft de Afdeling Heelkunde van het Leids Universitair Medisch Centrum (LUMC) besloten patiëntensimulaties op de computer in het onderwijs te gebruiken. Het LUMC heeft reeds vele jaren ervaring met het ontwikkelen en gebruik van dergelijke simulaties. ${ }^{2}$

\section{Dynamische Patiënt Simulator}

De afgelopen jaren is het programma Dynamische Patiënt Simulator (DPS) ontwikkeld, waarmee docenten casus kunnen creëren. ${ }^{4}$ Centraal in de simulatie staat de toestand van de patiënt. Veranderingen in deze toestand in de tijd worden gesimuleerd en de student kan deze beïnvloeden door diagnostische en therapeutische handelingen. Om de simulatie zo echt mogelijk te maken, kunnen de studenten beschikken over alle diagnostische en therapeutische mogelijkheden die de situatie waarin zij zich virtueel bevinden, toelaat. 5 De student moet deze mogelijkheden zelf verzinnen en wordt dus gedwongen zelfstandig te handelen.

Deze onderwijsvorm heeft een groot aantal pluspunten vergeleken met andere onderwijsvormen: 
- De DPS heeft alle voordelen die computerondersteund onderwijs ( $\mathrm{COO}$ ) ook heeft. Het kan als individueel onderwijs worden gebruikt.

- Studenten kunnen fouten maken en ervan leren. Aan het eind van een gesimuleerde casus krijgt de student feedback.

- De gelegenheid om opgedane kennis toe te passen is een stimulans voor de rest van het onderwijs.

- De DPS kan zowel aan de student als aan de docent feedback geven over het verloop van een casus.

De DPS registreert niet alleen de handelingen van de student, maar ook de momenten waarop de student niet handelt. Deze registratie wordt gebruikt bij de feedback na afloop van de casus. De auteur van een casus moet programmeren of een handeling goed of fout is. Bovendien kunnen ook de volgorde van de handelingen en het tijdstip van handelen beoordeeld worden. Deze beoordelingen resulteren uiteindelijk in een cijfer.

\section{Toetsing met behulp van de DPS}

In de preklinische fase van de studie geneeskunde in Leiden wordt voornamelijk gebruik gemaakt van schriftelijke examens, meestal om de zeer pragmatische reden dat grote aantallen studenten eenvoudiger te toetsen zijn met schriftelijke tentamens dan met andere toetsvormen. 67 Deze schriftelijke tentamens bestaan voor een groot deel uit meerkeuzevragen, waarbij de Leidse facultaire vragenbank een centrale positie inneemt. Er is een tendens om steeds meer van deze tentamens, met name de herkansingen, af te nemen met behulp van de computer. 89 Het is voor docenten moeilijk om meerkeuzevragen te maken waarmee inzicht wordt getoetst.

Docenten hebben over het algemeen het gevoel dat ze competentie van studenten beter in kunnen schatten met mondelinge examens. Een nadeel van mondelinge examens is dat het afnemen veel tijd kost. Deze vorm van examineren wordt in Leiden dan ook alleen toegepast tijdens de co-assistentschappen. Helaas blijkt mondeling examineren niet erg betrouwbaar te zijn. ${ }^{10}$

In de DPS wordt een klinische casus in een realistische setting gepresenteerd. ${ }^{11}$ De loop van een casus is onvoorspelbaar, omdat er geen vaste paden zijn voorgeprogrammeerd. Het verloop van de casus is afhankelijk van de diagnostische en therapeutische handelingen die de student kiest en de tijd die nodig is. Alle handelingen van de student worden, met een tijdsindicatie, door de computer opgeslagen. Het cijfer wordt na afloop van een casus als volgt berekend:

- Aan alle diagnostische (anamnese, lichamelijk en aanvullend onderzoek) en therapeutische handelingen kan de auteur van de casus negatieve (pNeg) of positieve ( $p$ Pos) punten toekennen. Tevens is het mogelijk de volgorde van de handelingen en/of de tijdstippen waarop de handelingen worden uitgevoerd te beoordelen.

- Met een regelsysteem kan de waarde van deze punten tijdens de duur van de casus beïnvloed worden.

- De auteur van de casus bepaalt vooraf zowel het minimaal te behalen aantal positieve punten (mPos) als het maximaal toelaatbare aantal negatieve punten $(\mathrm{mNeg})$ dat een student mag scoren.

- Het cijfer wordt berekend door de fractie van de positieve punten ten opzichte van het minimaal te behalen aantal positieve punten te nemen. Als het aantal positieve punten ( $\mathrm{pPos}$ ) dit minimum (mPos) overschrijdt, wordt de fractie op 1.0 gesteld. Dit getal wordt vermenigvuldigd met de omgekeerde fractie van de negatieve punten ten opzichte van het maxi- 
maal aantal negatieve punten dat verloren mag worden. In formulevorm ziet dat er als volgt uit:

$$
\begin{aligned}
& \text { cijfer }=10 x(\min (1, p \text { Pos } / \text { mPos }) x \\
& (1-\min (1, p N e g / m N e g)))
\end{aligned}
$$

Met deze formule wordt het cijfer weergegeven op een tienpuntsschaal.

Als een student een verkeerde keuze maakt bij de behandeling van de gesimuleerde patiënt, maar de gemaakte fout tijdens de simulatie onderkent en de gecreëerde problemen alsnog oplost, dan kan een regelsysteem de beoordeling zo aanpassen dat er een redelijke beoordeling volgt. Deze procedure geeft de docent een grotere vrijheid in het beoordelen van de student dan reeds bestaande score-algoritmen. ${ }^{12}$ Tevens kunnen er tijdens een casus (meerkeuze) vragen aan de student gesteld worden in een zeer realistische setting. Als een student bijvoorbeeld de patiënt voorstelt een broekprothese-operatie te ondergaan, kan de gesimuleerde patiënt vragen hoe groot het risico op overlijden is tijdens deze operatie. Het antwoord hierop kan in de beoordeling worden meegewogen.

Bij de feedback na afloop van de casus worden alle handelingen van de student behalve beoordeeld ook becommentarieerd. Daarnaast komen alle handelingen aan bod die volgens de auteur van de casus noodzakelijk waren en die de student niet heeft uitgevoerd. Dit maakt het voor de student inzichtelijk hoe de eindbeoordeling tot stand is gekomen.

\section{Discussie}

Toetsing met de DPS lijkt een aantal voordelen te bieden. Er is geen invloed van de examinator op het cijfer en elke student wordt dus op vergelijkbare wijze beoordeeld. Het afnemen van examens met de computer is efficiënt. Het implementeren van een casus is één tot twee weken werk. Daarna kost het afnemen van een toets weinig tot geen menskracht meer.
Er kleven ook nadelen aan deze toetsvorm. Aangezien er van studenten verwacht wordt dat zij hun kennis in klinische situaties kunnen gebruiken, betekent dit dat er impliciet ook kennis getoetst wordt. Mocht deze kennis bij studenten tijdens een bepaalde casus ontbreken, dan zal deze casus naar verwachting met onvoldoende resultaat door hen worden gemaakt. Daarom zal er altijd een aantal casus met verschillende onderwerpen aan de studenten moeten worden aangeboden om een goed eindoordeel te kunnen vellen. Tevens is het puntensysteem van de DPS nog arbitrair. Docenten kunnen op verschillende manieren punten toekennen aan diverse handelingen en situaties. Hetzelfde geldt overigens voor mondelinge examens. Daarom is het verstandig met verschillende docenten consensus te bereiken over de wijze waarop de puntentelling tot stand komt. ${ }^{13}$

Een punt van aandacht bij het gebruik van computertoetsen is het uiteindelijke cijfer. De meeste cijfers die tijdens de coassistentschappen worden toegekend variëren tussen de 7 en de $8 .{ }^{14} 15$ Aan deze hoge beoordelingen ligt waarschijnlijk een bepaald verwachtingspatroon van zowel studenten als docenten ten grondslag. Dit verwachtingspatroon speelt geen enkele rol als de beoordeling door een computer gedaan wordt, wat tot (voor de student) onverwachte resultaten kan leiden.

\section{Literatuur}

1. Metz JCM, Pels Rijcken-Van Erp Taalman Kip EH, Brand van den BWM. Raamplan 1994 artsopleiding; eindtermen van de artsopleiding. Nijmegen: Universitair Publikatiebureau, Katholieke Universiteit Nijmegen; 1994

2. Verbeek HA, Coffeng PPC, Lee WJM van der, Mouwen E. Cases: handleiding voor de auteur. CAT Benelux; 1987.

3. Bloemendaal PM, Baalen JM van, Vergeer MJP. Ontwikkeling van een Dynamische Patiëntsimulatie op de computer ter bevordering van het besliskundig proces bij studenten. In: Verweij AMJJ, Albersnagel EA, Cate ThJ ten, Denekens J, 
Dikkers JH, Remmen R, et al., redactie. Gezond onderwijs-7. Proceedings Gezond Onderwijs Congres 1997. Houten/ Diegem: Bohn Stafleu Van Loghum; 1997. p. 51-3.

4. Bloemendaal PM, Baalen JM van, Vergeer MPJ. The development of a dynamic patient simulator. In: Proceedings of the Eighth International Ottawa Conference. Ter perse.

5. Friedman CP. Anatomy of the clinical simulation. Acad Med 1995;70(3):205-9.

6. Dousma T, Horsten A. Tentamineren. Groningen: Wolters-Noordhoff; 1980.

7. Bloemendaal PM, Ruigrok MAM, Jong PGM de, Leeuwen $\mathrm{T}$ van, Windt $\mathrm{C}$ de. Tien jaar ervaring met de facultaire vragenbank Leiden. In: Smal JA, Cate ThJ ten, Denekens J, Dikkers JH, Remmen R, Spaai GWG, et al., redactie. Gezond onderwijs - 6; proceedings Gezond Onderwijs Congres 1996. Houten/Diegem: Bohn Stafleu Van Loghum; 1996. p. 27-9.

8. Leeuwen T van. Geautomatiseerd toetsen aan de PC. In: Toetsing in de basisopleiding en het postacademisch onderwijs. Leiden: Boerhaave Commissie postacademisch onderwijs in de geneeskunde; 1997. p. 117-31.

9. Leeuwen T van, Bloemendaal PM. Egel 3.0: een geautomatiseerd vragenbank- en toetssysteem. In: Smal JA, Cate ThJ ten, Denekens J, Dikkers JH, Remmen R, Spaai GWG, et al., redactie. Gezond onderwijs - 6; proceedings Gezond Onderwijs Congres 1996. Houten/ Diegem: Bohn Stafleu Van Loghum; 1997. p. 150-5.

10. Buitenhuis J, Zwierstra RP, Venekamp R, Torn Broers SM. Drie jaar ervaring met een geobserveerd en gestandaardiseerd artsexamen chirurgie. In: Houtkoop E, Pols J, Pollemans MC, Scherpbier AJJA, Verwijnen GM, redactie. Gezond onderwijs 3. 's-Gravenhage: Haagse Hogeschool; 1994. p. 91-4.

11. Bloemendaal PM, Baalen JM van, Vergeer MJP. De mogelijkheden van patiënt simulatie software in een curriculum geneeskunde. In: Mirande M, Riemersma J, Veen W, redactie. De digitale leer- omgeving. Groningen: Wolters-Noordhoff; 1997. p. 283-9.

12. Clauser BE, Ross LP, Clyman SG, Rose KM, Margolis MJ, Nungester RJ, et al. Development of a scoring algorithm to replace expert rating for scoring a complex performance-based assessment. Applied Measurement in Education 1997;10(4):345-58.

13. Clyman SG, Melnick DE, Clauser BE. Computerbased case simulation by the National Board of Medical Examiners of the United States. In: Jong PGM de, Bloemendaal PM, redactie. Toetsing in de basisopleiding en het postacademisch onderwijs. Leiden: Boerhaave Commissie Postacademisch Onderwijs in de Geneeskunde; 1997. p. 133-47.

14. Eijk AM van, Baalen JM van, Bloemendaal PM. De beoordeling van het co-assistentschap heelkunde in het Academisch Ziekenhuis Leiden na aanstelling van een assistent-coördinator onderwijs voor de kliniek. In: Smal JA, Cate ThJ ten, Denekens J, Dikkers JH, Remmen R, Spaai GWG, et al., redactie. Gezond onderwijs - 6; proceedings Gezond Onderwijs Congres 1996. Houten / Diegem: Bohn Stafleu Van Loghum; 1997. p. 84-8.

15. Cohen-Schotanus J. Cijfers voor co-schappen opnieuw ter discussie gesteld. In: Houtkoop E, Pols J, Pollemans MC, Scherpbier AJJA, Verwijnen GM, redactie. Gezond onderwijs - 3. 's-Gravenhage: Haagse Hogeschool; 1994. p. 127-9.

De auteurs:

P.M. Bloemendaal, arts/assistent-onderwijscoördinator, Afdeling Heelkunde, LUMC.

J.M. van Baalen, chirurg/onderwijscoördinator, Afdeling Heelkunde, LUMC.

S. Eggermont, programmeur-systeemanalist, Afdeling Heelkunde, LUMC.

Correspondentieadres:

P.M. Bloemendaal, Afdeling Heelkunde, K6-R, Postbus 9600, 2300 RC Leiden, tel.: 071 5263628,

e-mail: bloemendaal@rullf2.leidenuniv.nl.

\section{Summary}

At the end of the undergraduate curriculum, medical students are expected to be able to make independent decisions. The Department of Surgery of Leiden University Medical Center has developed the Dynamic Patient Simulator (DPS) to offer students the opportunity to practice independent decision making. At the centre of the computer-based simulation is the patient's condition as it changes over time. Students have to select the appropriate diagnostic and therapeutic strategies from those offered by the programme. The DPS records the student's actions as well as their order and timing. These data are used to calculate a mark, which is presented at the end of a case together with feedback on the student's performance. Because the DPS requires students to apply their knowledge in a clinical situation, the DPS can be used as a clinically oriented examination. (Bloemendaal P.M., Baalen J.M. van, Eggermont S.: The Dynamic Patient Simulator as an assessment tool. Dutch Journal of Medical Education 2000;19(3):92-95.) 